\title{
CORRECTION
}

\section{Correction to: Gadobutrol: A Review in Contrast-Enhanced MRI and MRA}

\author{
Lesley J. Scott ${ }^{1}$
}

Published online: 23 August 2018

(c) Springer Nature Switzerland AG 2018

\section{Correction to: Clinical Drug Investigation 2018;38(8):773-784 https://doi.org/10.1007/s40261-018-0674-9}

Page 774, Table 1, Ligand structure row/gadobenate dimeglumine column: The cell entry in the "Gadobenate dimeglumine" column, which previously read:

"Macrocyclic"

should read:

"Linear"

The corrected Table 1 is:

Table 1 Key chemical and physiochemical properties of selected gadolinium-based contrast agents

\begin{tabular}{|c|c|c|c|c|c|}
\hline Property & Gadobutrol & Gadoteridol & $\begin{array}{l}\text { Gadoterate } \\
\text { meglumine }\end{array}$ & $\begin{array}{l}\text { Gadobenate } \\
\text { dimeglumine }\end{array}$ & $\begin{array}{l}\text { Gadopentetate } \\
\text { dimeglumine }\end{array}$ \\
\hline Ligand structure & Macrocyclic & Macrocyclic & Macrocyclic & Linear & Linear \\
\hline Charge & Non-ionic & Non-ionic & Ionic & Ionic & Ionic \\
\hline Concentration (mol/L) & 1 & 0.5 & 0.5 & 0.5 & 0.5 \\
\hline Osmolality at $37^{\circ} \mathrm{C}\left(\mathrm{osmol} / \mathrm{kg} \mathrm{H}_{2} \mathrm{O}\right)$ & 1.6 & 0.63 & 1.35 & 1.97 & 1.96 \\
\hline Relaxivities $r_{1} / r_{2}$ in plasma at $37{ }^{\circ} \mathrm{C}(\mathrm{mmol} / \mathrm{L} / \mathrm{s})$ & $5.2 / 6.1$ & $4.1 / 5.0$ & $3.6 / 4.3$ & $6.3 / 9.2$ & $4.1 / 4.6$ \\
\hline Viscosity at $37^{\circ} \mathrm{C}$ & 4.96 & 1.3 & 2.0 & 5.3 & 2.9 \\
\hline Thermodynamic complex stability $\left(\log \mathrm{K}_{\mathrm{eq}}\right)$ & 21.8 & 23.8 & 25.8 & 22.6 & 22.1 \\
\hline
\end{tabular}

Adapted from Scott [5]

The original article was corrected.

The original article can be found online at https://doi.org/10.1007/ s40261-018-0674-9.

Lesley J. Scott

demail@springer.com

1 Springer, Private Bag 65901, Mairangi Bay, Auckland 0754, New Zealand 